\title{
Risk factors of Helicobacter pylori infection in an urban community in Northeast Brazil and the relationship between the infection and gastric diseases
}

\author{
Irigrácin Lima Diniz Basílio ${ }^{[1],[2], ~ M a r i a ~ d e ~ F a ́ t i m a ~ C e l i n o ~ C a t a ̃ o[1], ~}$ \\ Janilson Dantas de Sousa Carvalho ${ }^{[1]}$, Francisco Paulo Freire-Neto ${ }^{[3],[4],[5],}$ \\ Leonardo Capristano Ferreira ${ }^{[3],[4],[5]}$ and Selma Maria Bezerra Jerônimo ${ }^{[2],[3],[4],[5]}$
}

[1]. Universidade Federal de Campina Grande, Campina Grande, PB, Brasil.

[2]. Programa de Pós-Graduação em Saúde, Centro de Ciências da Saúde, Universidade Federal do Rio Grande do Norte, Natal, RN, Brasil. [3]. Departamento of Bioquímica, Centro de Biociências, Universidade Federal do Rio Grande do Norte, Natal, RN, Brasil. [4]. Instituto de Medicina Tropical Rio Grande do Norte, Universidade Federal do Rio Grande do Norte, Natal, RN, Brasil. [5]. Instituto Nacional de Ciência e Tecnologia de Doenças Tropicais, Natal, RN, Brasil.

\begin{abstract}
Introduction: Helicobacter pylori, a water contaminant, is the primary pathogenic agent associated with gastric diseases in humans. Exposure to H. pylori is more likely higher in developing countries. This study aimed to evaluate the risk factors associated with $H$. pylori infection in patients undergoing endoscopy to validate the cause of dyspeptic symptoms in an urban population in northeast Brazil and to compare the urease test and polymerase chain reaction assay results with the histopathological findings. Methods: We evaluated 200 of 759 individuals with dyspeptic complaints from Campina Grande, State of Paraiba, northeast Brazil. Patients underwent endoscopy, followed by gastric biopsies. Logistic regression analysis was performed to adjust for confounders and to determine significant risk factors of dyspeptic disorders. Results: Women accounted for $72.5 \%$ $(145 / 200)$ of the participants. Approximately 59.8\% (120/200) of the samples tested positive for $H$. pylori based on histological examinations. The specificity of polymerase chain reaction assay was higher than that of the urease test $(77 \% \mathrm{vs} .64 \%$, $\mathrm{p}=0.034)$. City drinking water [odds ratio (OR): 2.6; 95\% confidence interval (CI): 1.3-5.21; $\mathrm{p}=0.004$ ] and smoking (OR: 4.0; 95\% CI: $1.13-14.5 ; \mathrm{p}=0.031$ ) were the risk factors of $H$. pylori infection. Belching was the most common symptom associated with $H$. pylori infection $(\mathrm{p}=0.05)$. Conclusions: The increased risk of $H$. pylori infection associated with non-treated water consumption indicates the need for improvements in public water treatment and better sanitary conditions because these can be a source of not only H. pylori infections but also other water-borne pathogen infections.
\end{abstract}

Keywords: Epidemiology. Helicobacter pylori. Risk factors. Brazil.

\section{INTRODUCTION}

Helicobacter pylori is the primary etiologic agent involved in gastric diseases in humans with worldwide distributions ${ }^{1}$. In 2005, H. pylori was identified as a microbiologic contaminant of water, and its role in gastric diseases was further assessed $d^{2-4}$. Improvements in sanitary conditions and higher human development indices have reduced the prevalence rate of H. pylori infection in developed countries. However, the prevalence rate in developing countries remains high ${ }^{1}$.

Populations with lower socioeconomic levels present with higher prevalence rates of $H$. pylori infection ${ }^{5-7}$. In developing countries, the prevalence rate is higher than $70 \%$, whereas in

Corresponding Author: $\mathrm{Dr}^{\mathrm{a}}$ Selma Maria Bezerra Jerônimo.

e-mail: selma.b.jeronimo@gmail.com

Received 10 November 2016

Accepted 18 April 2018 developed countries, such as Canada, Australia, and Switzerland, the prevalence rate can be as low as $30 \%$. The prevalence rate of $H$. pylori infection in Brazil, particularly in its poorest areas, is similar to that in Africa, which is around $70-90 \%{ }^{1,8}$.

Brazil has a population of over 200 million individuals with varying ethnic and geographic backgrounds. The country is heterogeneous with respect to sanitary coverage, and a large proportion of its population still do not have access to highquality water ${ }^{9}, 10$. Access to high-quality water is not evenly distributed across Brazil and is highly dependent on sanitary facilities and infrastructure.

H. pylori is considered a carcinogen because it can induce the development of lesions such as atrophy, metaplasia, and dysplasia, leading to adenocarcinoma ${ }^{11,12}$. A meta-analysis showed that the risk of developing gastric cancer increased by two-fold when individuals were infected with $H$. pylori strains that contained the $\operatorname{cag} A+$ gene $^{13-15}$. The use of antibiotic therapy for 
the treatment of $H$. pylori infection decreased the development of gastric cancer, particularly when the treatment was started prior to the onset of precursor lesions. Controlling environmental factors, such as high salt intake, nitrites, and smoking, has decreased the burden of $H$. pylori infection ${ }^{14}$. Therefore, decreasing the risk factors of $H$. pylori infection is one of the measures that can prevent the development of gastric cancer. This study aimed to evaluate the risk factors associated with $H$. pylori infection in patients undergoing endoscopy to validate the cause of dyspeptic symptoms in an urban population in northeast Brazil and to compare the urease test and polymerase chain reaction (PCR) assay results with histopathological findings.

\section{METHODS}

\section{Study participants}

The study was conducted in Campina Grande, State of Paraiba, Northeast Brazil, a city with a population of 402,912 inhabitants. Both male and female participants and those aged 18 years and older who agreed to participate in the study were recruited from a referral center for gastric diseases. Participants were excluded from the study if they used nonsteroidal antiinflammatory proton pump inhibitors or antibiotics a month prior to examination or if they lived outside the City of Campina Grande. We did not include participants living outside Campina Grande because we could not validate the source of drinking water. Moreover, participants who were pregnant, those who underwent gastrectomy, or those who were unable to undergo endoscopy were excluded. Participants were asked to complete a survey questionnaire with demographic, social, economic, and lifestyle questions. Of the 1,257 participants scheduled to undergo endoscopy between February 2012 and October 2012, 759 underwent endoscopy, of which 200 met the inclusion criteria and were recruited.

\section{Endoscopy assessment}

After clinical evaluation, the participants underwent endoscopy, which was performed by a trained endoscopist. Macroscopic data included topography, localization, and type of injury. Systemic anesthesia was conducted with midazolam and fentanyl. During the procedure, gastric biopsies were carried out (two in the antrum, two in the body, and one in the incisura angularis) for histological study, which is in accordance with the recommendations of the Brazilian Society of Digestive Endoscopy.

\section{Determination of Helicobacter pylori infection}

H. pylori infection was determined via histological examination, urease test, and PCR. Histological examination is the gold standard test for $\mathrm{H}$. pylori infection. Two fragments were collected from the antrum to determine the presence of urease (Urotest Kit, RenyLab, Barbacena, MG, Brazil), and all test results were read within 24 hours of tissue collection.

Tissue fragments were fixed in $10 \%$ formalin and were prepared according to standard histology protocol. Slides were stained with hematoxylin-eosin and were analyzed by a single pathologist. Deoxyribonucleic acid (DNA) was extracted from formalin-fixed paraffin-embedded tissues obtained from gastric biopsy ${ }^{16}$. Eight slices $(10 \mu \mathrm{m})$ from each sample were collected, and DNA extraction was performed using QIAamp DNA from paraffin-embedded tissues (QIAGEN Inc., Chatsworth, California, the USA) according to the manufacturer's instructions. The presence of $H$. pylori DNA was confirmed using PCR amplification of the 16S-ribosomal DNA (rDNA) using specific primers (5'-CTGGAGAGACTAAGCCCTCC-3' and $5^{\prime}$-GAGGAATACTCATTGCGAAGGCGA-3' $]^{16}$. PCR reactions were performed with $20 \mu \mathrm{L}$ containing $1 \times \mathrm{PCR}$ buffer, $0.2 \mathrm{mmol} / \mathrm{L}$ of each deoxynucleotide, $0.2 \mu \mathrm{M}$ of each primer, and 1 unit of Taq polymerase. The PCR cycles were $95^{\circ} \mathrm{C}$ for $2 \mathrm{~min} ;\left(95^{\circ} \mathrm{C}\right.$ for $1 \mathrm{~min} ; 58^{\circ} \mathrm{C}$ for $1 \mathrm{~min}$; and $72^{\circ} \mathrm{C}$ for $1 \mathrm{~min}$ ) $40 \mathrm{X} ; 72^{\circ} \mathrm{C}$ for $10 \mathrm{~min}$; and $10^{\circ} \mathrm{C}$. Gel electrophoresis ( $2 \%$ agarose) was used to determine whether PCR products had the correct length of $229 \mathrm{bp}$. Ten samples positive on PCR were sent for sequencing at Macrogen Inc. (Seoul, Korea) to confirm the results of the PCR assay.

\section{Histopathological examination}

The diagnoses were made according to the updated Sydney System for chronic gastritis when the presence of lymphocytes in the lamina propria was higher than expected ${ }^{17}$. The existence of plasma cells was considered an indicator of chronic inflammation. The presence of neutrophils was considered a marker of active gastritis. The loss of glandular tissue was considered a marker of gastric mucosal atrophy ${ }^{17}$.

\section{Ethical considerations}

The study protocol was reviewed and approved by the ethical review board of Universidade Federal do Rio Grande do Norte. The study was conducted in accordance with the ethical standards of the Brazilian national committee of Ethics in inhuman research, which follows the principles of the Declaration of Helsinki. The approval number is CAAE: 0251.0.051.127-10. Informed consent was obtained from all the participants.

\section{Statistical analysis}

The comparisons were based on the $H$. pylori infection status, which was determined via histological examination. Fisher's exact and Wilcoxon rank-sum tests were used to compare categorical and continuous variables, respectively. The comparison of sensitivity and specificity between diagnostic methods (Urease vs PCR) were determined by McNemar's chisquare. Logistic regression models were established to further examine demographic, lifestyle, and socioeconomic factors associated with the risk of developing $H$. pylori infections. All analyses were performed using Stata (Stata Statistical Software: Release 11. College Station, TX, United States) with $95 \%$ confidence interval $(\mathrm{CI})$, and we set the significance level $(\alpha)$ at 0.05 .

\section{RESULTS}

\section{Comparison of diagnostic methods for $\boldsymbol{H}$. pylori infection}

The prevalence rate of $H$. pylori infection was $69.5 \%$ $(139 / 200), 60 \%(120 / 200)$, and $58 \%(116 / 200)$ via the urease test, histological examination, and PCR assay, respectively. 
The urease test was more sensitive than PCR assay [92\% ( $95 \%$ CI: $0.85,0.96)$ vs. $82 \%$ (95\% CI: $0.74,0.89), p=0.012]$ for diagnosing $H$. pylori infection, whereas PCR assay had a higher specificity than the urease test [78\% (95\% CI: $0.67,0.86)$ vs. $64 \%(95 \%$ CI: $0.52,0.74), p=0.034]$. Table 1 shows the performances of the two methods with respect to histological examination, which is the gold standard test for $H$. pylori infection.

\section{Demographic and clinical characteristics of the study population}

All participants were from the same geographic region; $72.5 \%(145 / 200)$ of the participants were women. The sociodemographic data of the population are shown in Table 2. No difference was observed in the educational and socioeconomic levels of the $H$. pylori-positive or $H$. pylorinegative groups. Current smoking habits [adjusted odds ratio (OR): 5.19; 95\% CI: $1.29-20.86 ; \mathrm{p}=0.02]$ and intake of nontreated water (OR: $2.20 ; 95 \%$ CI: $1.02-4.72 ; \mathrm{p}=0.044)$ were associated with $H$. pylori infection (Table 3). Other variables, such as age, hand washing, and cup sharing, were not associated with H. pylori infection (Table 3).

\section{Helicobacter pylori infection and its relationship with gastric diseases}

Gastritis and duodenal ulcer were common findings in both individuals with and without $H$. pylori infection. Belching was the only symptom $(\mathrm{p}=0.05)$ associated with $H$. pylori infection (Table 4). There was no association between H. pylori infection and a family history of either peptic ulcer $(\mathrm{p}=0.457)$ or gastric cancer $(\mathrm{p}=0.447)$ (Table 4). Mild gastritis was more frequently observed in individuals who were $H$. pylori negative $(\mathrm{p}<0.001)$ than in those with moderate or severe gastritis, which was commonly associated with $H$. pylori-positive individuals $(p<0.001)$ (Table 5). No difference was observed between the two groups in terms of gastroduodenal ulcer $(\mathrm{p}=0.474)$.
There was no association between alcohol intake $(\mathrm{p}>0.05)$ and the grade of inflammation. Cigarette smoking $(p=0.020)$ and consumption of municipal water $(\mathrm{p}=0.044)$ were associated with mild and moderate gastritis.

\section{DISCUSSION}

This is the first study conducted in the State of Paraíba, Northeast Brazil that assessed the effect of sociodemographic factors on the development of $H$. pylori infection. This pathogen affects half of the world's population, and it exceeds $80 \%$ in developing countries ${ }^{1}$. The prevalence rate of $H$. pylori infection was higher in the population who used non-treated water. These results are consistent with those of studies conducted in other countries in South America and in the other regions of Brazil ${ }^{1}$. Although Brazil has the eighth largest economy, it still has epidemiological characteristics similar to those of developing countries, where the prevalence rate of $H$. pylori infection is higher than $80 \%$. Zaterka et al. assessed 1,008 blood donors in São Paulo, and their results showed that the prevalence of $H$. pylori infection was also high, regardless of $\operatorname{sex}^{18}$.

H. pylori infection was most commonly observed in adults with an average age of 40 years. The prevalence of the infection among elderly individuals in Brazil is usually high, which is greater than $68 \%$ of the cases. Our results are in accordance with those of other studies. Gasbarrini et al. assessed health professionals in Rome, Italy and found that individuals who are older and those with fathers with fewer years of education were more likely to be $H$. pylori positive ${ }^{19}$. Another study conducted in Kuwait revealed a higher prevalence in women younger than 30 years $^{20}$.

Income level, educational level, and household crowding were similar in our study population. The association between an increased risk of $H$. pylori infection and coffee consumption was not statistically significant. $H$. pylori infection was more common among smokers and drinkers, regardless of

TABLE 1: Performance of the urease test and PCR for the diagnosis of Helicobacter pylori using histological examination as the gold standard test.

\begin{tabular}{lcccc}
\hline & \multicolumn{2}{c}{ Histological examination } & positive & Total \\
\cline { 3 - 4 } & nest & & \\
Urease & & 10 & 61 \\
negative & 51 & 110 & 139 \\
positive & 29 & 120 & 200 \\
total & 80 & & 20 \\
\hline
\end{tabular}

PCR

$\begin{array}{lccc}\text { negative } & 62 & 21 & 83 \\ \text { positive } & 18 & 98 & 116 \\ \text { total } & 80 & 119^{*} & 199\end{array}$

PCR: polymerase chain reaction. Urease: sensitivity $=110 / 120=92 \%$ and specificity $=51 / 80=64 \%$. PCR: sensitivity $=98 / 119^{*}=82 \%$ and specificity $=$ $62 / 80=78 \%$. ${ }^{*}$ One sample failed in the PCR assay. 
TABLE 2: Characteristics of the study population in accordance to Helicobacter pylori infection.

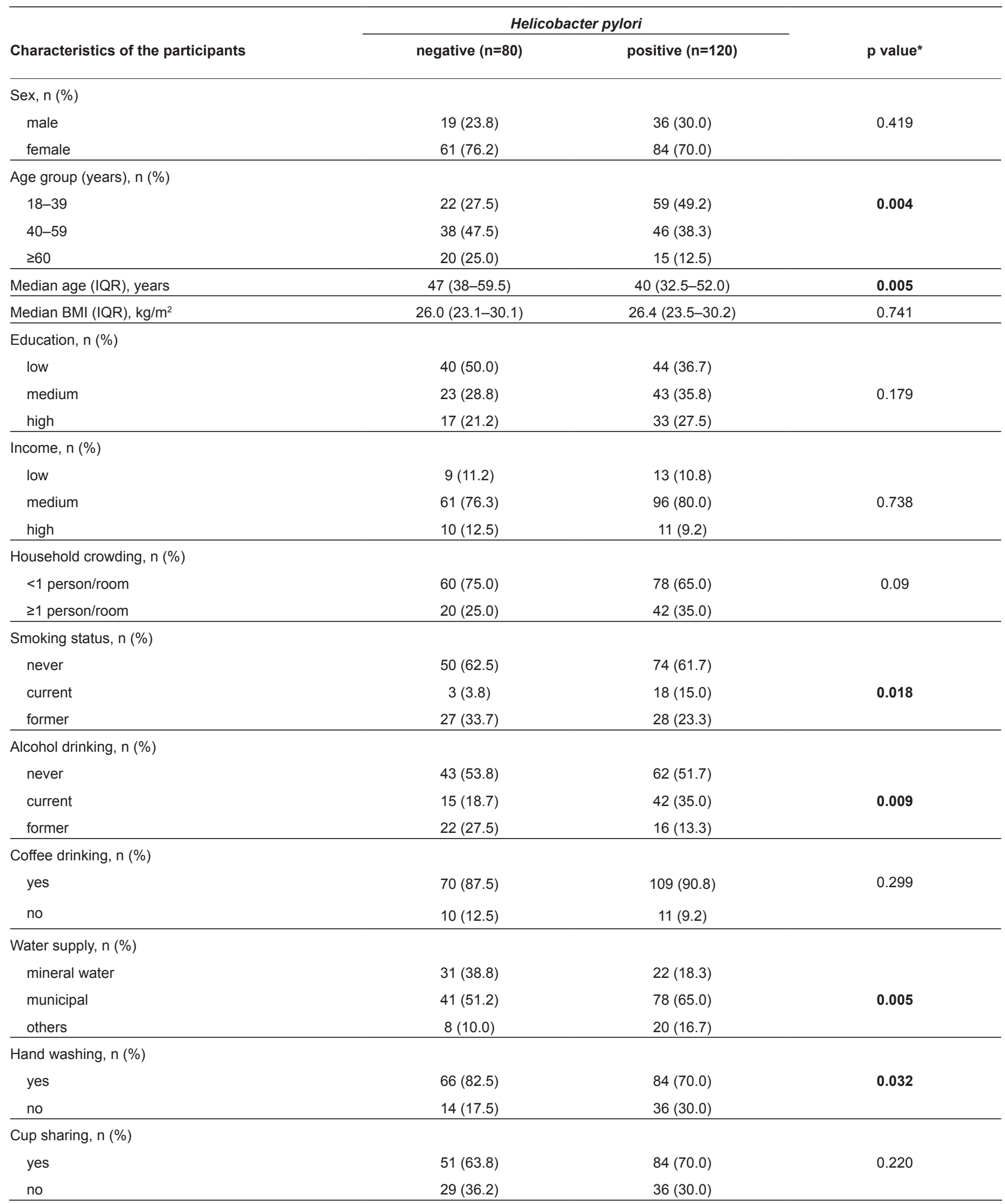

IQR: interquartile range; BMI: body mass index. *Fisher's exact test was used for categorical variables, and Wilcoxon rank-sum test was utilized for. quantitative variables. 
TABLE 3: Risk factors of Helicobacter pylori infection.

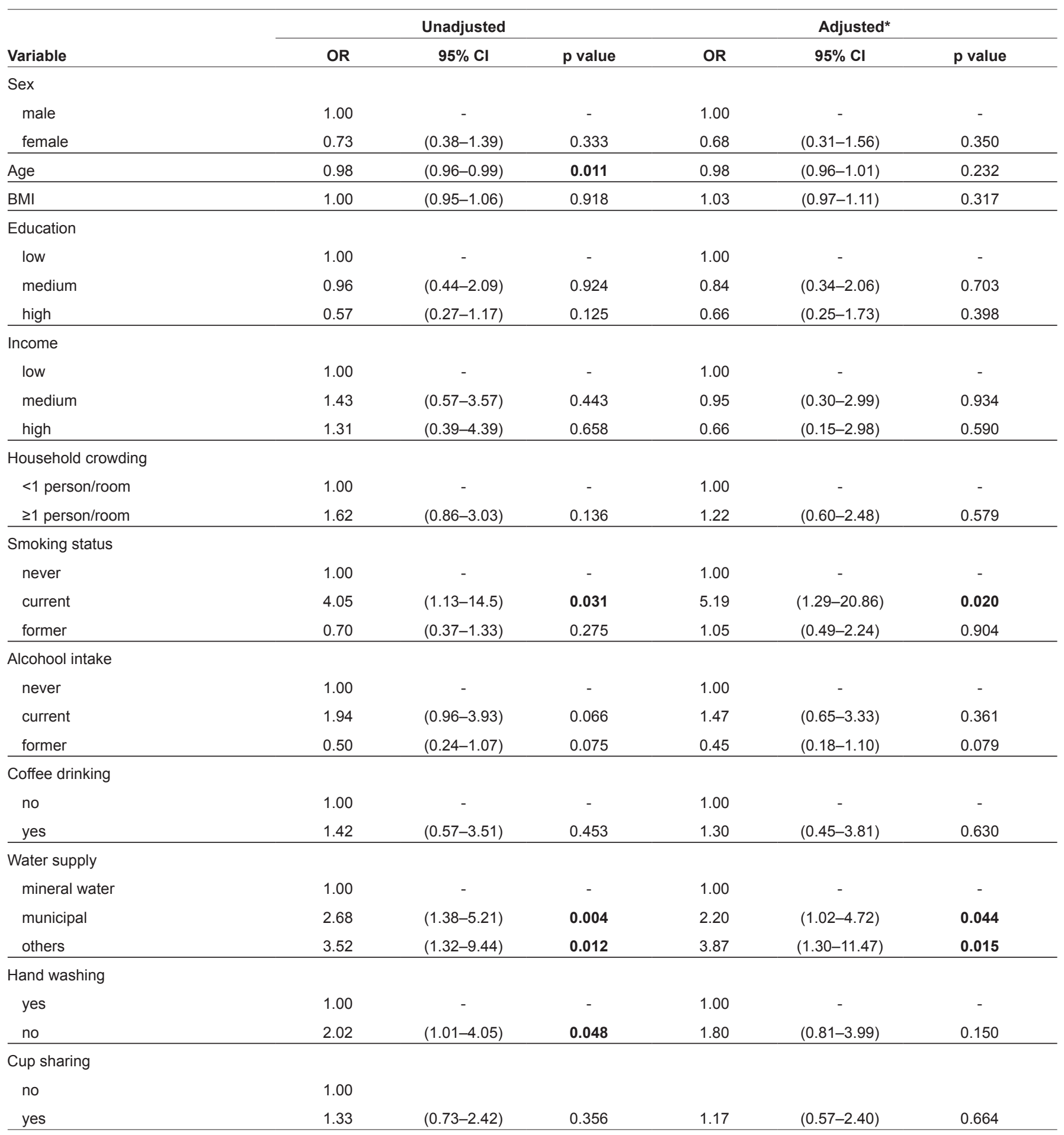

OR: odds ratio; $95 \% \mathrm{Cl}$ : confidence interval 95\%. ${ }^{*}$ The multiple logistic regression model included all variables mentioned in Table 3 as covariates.

whether they were light or heavy consumers. Smoking has been considered a risk factor of $H$. pylori infection ${ }^{18,21,22}$. The association between $H$. pylori infection and smoking has been attributed to socioeconomic conditions. Furthermore, smoking is a major risk factor for peptic ulcer disease because it stimulates gastric acid secretion and compromises the mucosal barrier, resulting in gastric atrophy and potentially leading to the development of cancer ${ }^{23}$. The association between two or more risk factors and H. pylori infection in the same patient also increases the risk of ulcer development ${ }^{24}$. Chen et al. showed that smoking was associated with an increased risk of duodenal ulcer in patients with $H$. pylori infection ${ }^{25}$. Infection stimulates the production of pepsinogen and decreases mucous production, leading to more pathology. H. pylori infection was common among drinkers. However, no association was found after controlling for confounders, as observed in a previous study ${ }^{26}$. 
TABLE 4: Clinical findings in accordance to Helicobacter pylori infection.

\begin{tabular}{|c|c|c|c|}
\hline \multirow[b]{2}{*}{ Clinical findings } & \multicolumn{2}{|c|}{ Helicobacter pylori } & \multirow[b]{2}{*}{ p value* } \\
\hline & negative $(n=80)$ & positive $(n=120)$ & \\
\hline \multicolumn{4}{|l|}{ Symptoms, n (\%) } \\
\hline vomiting & $11(13.8)$ & $13(10.8)$ & 0.341 \\
\hline heartburn & $49(61.3)$ & $83(69.2)$ & 0.157 \\
\hline loss of appetite & $12(15.0)$ & $16(13.4)$ & 0.447 \\
\hline early satiety & $6(7.5)$ & $9(7.5)$ & 0.602 \\
\hline belching & $11(13.8)$ & $29(24.2)$ & 0.050 \\
\hline regurgitation & $5(6.3)$ & $12(10.0)$ & 0.254 \\
\hline hiccups & $7(8.8)$ & $11(11.2)$ & 0.565 \\
\hline peptic ulcer & $20(25.0)$ & $28(23.3)$ & 0.457 \\
\hline gastric cancer & $12(15.0)$ & $16(13.3)$ & 0.447 \\
\hline
\end{tabular}

*Each symptom was compared in a $2 \times 2$ table using one-sided Fisher's exact test.

TABLE 5: Microscopy (histology) findings considering the presence of Helicobacter pylori.

\begin{tabular}{|c|c|c|c|}
\hline Microscopic findings, $n$ (\%) & \multicolumn{2}{|c|}{ Helicobacter pylori* } & p value** \\
\hline gastric atrophy & $9(11.3)$ & $24(20.0)$ & 0.073 \\
\hline mild gastritis & $38(47.5)$ & $18(15.0)$ & $<0.001$ \\
\hline
\end{tabular}

*Participants who had multiple symptoms. **Each finding was compared in a $2 \times 2$ table using Fisher's exact test.

In our study, individuals who consumed non-treated water and did not wash their hands before meals were more likely to acquire the infection. Sharing of cups among family members was not associated with the development of the infection. H. pylori is considered to be one of the microbiological contaminants of water. The viability of the bacteria is dependent on temperature conditions, which are ideal in the tropics, and this strengthens the assumption that contaminated water can be a natural source of infection ${ }^{4,27}$. The presence of $H$. pylori in non-treated water samples has been reported in other studies ${ }^{10}$. Campina Grande ranked $29^{\text {th }}$ in water quality in Brazil, and it still does not have complete sewage coverage. However, because of frequent water shortage, individuals are more likely to store water at home, and the risk of contamination becomes higher. Hand washing has contributed to a reduction in infections, particularly in the gastrointestinal tract ${ }^{18,28}$.

Belching was associated with $H$. pylori infection, although it has a borderline $\mathrm{p}$ value. Dyspepsia, which is defined as pain or discomfort in the upper abdomen, is the main clinical manifestation in most patients. Usually, this symptom causes participants to seek medical help, and these individuals are then required to undergo endoscopy ${ }^{11}$. Moreover, heartburn and epigastric pain were symptoms commonly associated with the persistence of $H$. pylori infection in human immunodeficiency virus-positive individuals ${ }^{29}$. Inflammation of the gastric mucosa increased with exposure to the bacteria. We found more H. pylori-positive patients with chronic gastritis, and this result is in accordance with the findings showing that chronic infection increases the severity of gastritis ${ }^{30}$.

In conclusion, the prevalence rate of $H$. pylori was high in patients dyspeptic disorders and was associated with the severity of gastritis, and this increased the awareness of the need to improve the city's non-treated water as a primary intervention to decrease $H$. pylori infection. PCR is a sensitive and specific diagnostic method that can be implemented in pathology 
laboratories and can be used as a confirmatory assay for $H$. pylori infection. In addition, it can help identify the genotype strains of $H$. pylori that contain the $\operatorname{cag} A+$ gene associated with neoplastic development ${ }^{13}$.

\section{Acknowledgments}

The authors would like to acknowledge Angela Toepp, MS, of the University of Iowa for her critical review of the manuscript.

\section{Conflict of interest}

The authors declare that there is no conflict of interest.

\section{Financial support}

This work was supported in part from a grant from the Conselho Nacional de Desenvolvimento Científico e Tecnológico (CNPq).

\section{REFERENCES}

1. Hunt RH, Xiao SD, Megraud F, Leon-Barua R, Bazzoli F, van der Merwe S, et al. Helicobacter pylori in developing countries. World Gastroenterology Organisation Global Guideline. J Gastrointestin Liver Dis. 2011;20(3)299-304.

2. Rodrigues MN, Queiroz DM, Bezerra Filho JG, Pontes LK, Rodrigues RT, Braga LL. Prevalence of Helicobacter pylori infection in children from an urban community in north-east Brazil and risk factors for infection. Eur J Gastroenterol Hepatol. 2004;16(2):201-5

3. Khan A, Farooqui A, Kazmi SU. Presence of Helicobacter pylori in drinking water of Karachi, Pakistan. J Infect Dev Ctries. 2012;6(3):251-5.

4. Konishi K, Saito N, Shoji E, Takeda H, Kato M, Asaka M, et al. Helicobacter pylori: longer survival in deep ground water and sea water than in a nutrient-rich environment. APMIS. 2007;115(11):1285-91.

5. Hegarty JP, Dowd MT, Baker KH. Occurrence of Helicobacter pylori in surface water in the United States. J Appl Microbiol. 1999;87(5):697-701.

6. Parkin DM. The global health burden of infection-associated cancers in the year 2002. Int J Cancer. 2006;118(12):3030-44.

7. Parente JM, da Silva BB, Palha-Dias MP, Zaterka S, Nishimura NF, Zeitune JM. Helicobacter pylori infection in children of low and high socioeconomic status in northeastern Brazil. Am J Trop Med Hyg. 2006;75(3):509-12.

8. Ben MK, Fendri C, Battikh H, Garnier M, Zribi M, Jlizi A, et al. Multiple and mixed Helicobacter pylori infections: Comparison of two epidemiological situations in Tunisia and France. Infect Genet Evol. 2016;37:43-8.

9. Braga LL, Oliveira MA, Goncalves MH, Chaves FK, Benigno TG, Gomes AD, et al. CagA phosphorylation EPIYA-C motifs and the vacA i genotype in Helicobacter pylori strains of asymptomatic children from a high-risk gastric cancer area in northeastern Brazil. Mem Inst Oswaldo Cruz. 2014;109(8):1045-9.

10. Queiroz DM, Carneiro JG, Braga-Neto MB, Fialho AB, Fialho AM, Goncalves MH, et al. Natural history of Helicobacter pylori infection in childhood: eight-year follow-up cohort study in an urban community in northeast of Brazil. Helicobacter. 2012;17(1):23-9.

11. Malfertheiner P, Megraud F, O'Morain C, Bell D, Bianchi PG, Deltenre M, et al. Current European concepts in the management of Helicobacter pylori infection--the Maastricht Consensus Report. The European Helicobacter Pylori Study Group (EHPSG). Eur J Gastroenterol Hepatol. 1997;9(1):1-2.
12. Malfertheiner P, Dominguez-Munoz JE. Rationale for eradication of Helicobacter pylori infection in duodenal ulcer disease. Clin Ther. 1993;15(Suppl B):37-48.

13. Matos JI, de Sousa HA, Marcos-Pinto R, Dinis-Ribeiro M. Helicobacter pylori $\mathrm{CagA}$ and VacA genotypes and gastric phenotype: a meta-analysis. Eur J Gastroenterol Hepatol. 2013;25(12):1431-41.

14. Nakajima S, Nishiyama Y, Yamaoka M, Yasuoka T, Cho E. Changes in the prevalence of Helicobacter pylori infection and gastrointestinal diseases in the past 17 years. J Gastroenterol Hepatol. 2010;25(Suppl 1):S99-S110.

15. Rugge M. Gastric Cancer Risk in Patients with Helicobacter pylori Infection and Following Its Eradication. Gastroenterol Clin North Am. 2015;44(3):609-24.

16. Scholte GH, van Doorn LJ, Quint WG, Lindeman J. Polymerase chain reaction for the detection of Helicobacter pylori in formaldehyde-sublimate fixed, paraffin-embedded gastric biopsies. Diagn Mol Pathol. 1997;6(4):238-43.

17. Stolte M, Meining A. The updated Sydney system: classification and grading of gastritis as the basis of diagnosis and treatment. Can J Gastroenterol. 2001;15(9):591-8.

18. Zaterka S, Eisig JN, Chinzon D, Rothstein W. Factors related to Helicobacter pylori prevalence in an adult population in Brazil. Helicobacter. 2007;12(1):82-8.

19. Gasbarrini A, Anti M, Franceschi F, Armuzzi A, Cotichini R, Ojetti V, et al. Prevalence of and risk factors for Helicobacter pylori infection among healthcare workers at a teaching hospital in Rome: the Catholic University Epidemiological Study. Eur J Gastroenterol Hepatol. 2001;13(2):185-9.

20. Alazmi WM, Siddique I, Alateeqi N, Al-Nakib B. Prevalence of Helicobacter pylori infection among new outpatients with dyspepsia in Kuwait. BMC Gastroenterol. 2010;10:14.

21. Gikas A, Triantafillidis JK, Apostolidis N, Mallas E, Peros G, Androulakis G. Relationship of smoking and coffee and alcohol consumption with seroconversion to Helicobacter pylori: a longitudinal study in hospital workers. J Gastroenterol Hepatol. 2004;19(8):927-33.

22. Shimamoto T, Yamamichi N, Kodashima S, Takahashi Y, Fujishiro $\mathrm{M}$, Oka M, et al. No association of coffee consumption with gastric ulcer, duodenal ulcer, reflux esophagitis, and non-erosive reflux disease: a cross-sectional study of 8,013 healthy subjects in Japan. PLoS One. 2013;8(6):e65996.

23. Reddy KM, Chang JI, Shi JM, Wu BU. Risk of Gastric Cancer Among Patients With Intestinal Metaplasia of the Stomach in a United States Integrated Healthcare System. Clin Gastroenterol Hepatol. 2016;14(10):1420-5.

24. Koivisto TT, Voutilainen ME, Farkkila MA. Effect of smoking on gastric histology in Helicobacter pylori -positive gastritis. Scand J Gastroenterol. 2008;43(10):1177-83.

25. Chen TS, Lee YC, LiFY, Chang FY. Smoking and hyperpepsinogenemia are associated with increased risk for duodenal ulcer in Helicobacter pylori-infected patients. J Clin Gastroenterol. 2005;39(8):699-703.

26. Schottker B, Adamu MA, Weck MN, Brenner H. Helicobacter pylori infection is strongly associated with gastric and duodenal ulcers in a large prospective study. Clin Gastroenterol Hepatol. 2012;10(5):487-93.

27. Khan A, Farooqui A, Raza Y, Rasheed F, Manzoor H, Akhtar SS, et al. Prevalence, diversity and disease association of Helicobacter pylori in dyspeptic patients from Pakistan. J Infect Dev Ctries. 2013;7(3):220-8.

28. Brown LM, Thomas TL, Ma JL, Chang YS, You WC, Liu WD, et al. Helicobacter pylori infection in rural China: demographic, lifestyle and environmental factors. Int J Epidemiol. 2002;31(3):638-45.

29. Fialho AB, Braga-Neto MB, Guerra EJ, Fialho AM, Fernandes KC, Sun JL, et al. Low prevalence of $H$. pylori infection in HIV-positive patients in the northeast of Brazil. BMC Gastroenterol. 2011;11:13.

30. Gobert AP, Wilson KT. Human and Helicobacter pylori Interactions Determine the Outcome of Gastric Diseases. Curr Top Microbiol Immunol. 2017;400:27-52. 